\title{
Peculiarities of Initial Piano Pedagogy in Contemporary China
}

\author{
Yanchen Liu \\ Department of musical Upbringing and Education \\ Herzen State Pedagogical University of Russia \\ Saint-Petersburg, Russia
}

\begin{abstract}
The article deals with peculiarities of the Chinese initial piano pedagogy. The author points out the main principles of forming national methodic in musical education, presents the forms of initial teaching piano in China, finds out correlations between technical training and artistic aesthetics. In whole, the methodic of teaching piano playing in China is looked through as a pedagogic problem.
\end{abstract}

Keywords-piano pedagogy; primary musical education; Chinese national methodic; playing the piano; composer's oeuvre for children

\section{INTRODUCTION}

The initial period of studying to play an instrument is crucial for all future activities of a musician. Obtained in this time knowledge and skills largely determine the path of the learner. To correct defects inherent in the initial stage, is incredibly difficult, extremely unproductive on time and requires great skill of a teacher. Pedagogical practice in China in general is characterized by a lack of a research in the field of methodology. The purpose of this article is to identify the peculiarities of the initial stage of studying in Chinese piano pedagogy.

\section{FORMS OF STUDYING PIANO PLAYING IN CHINA}

In modern Chinese initial piano education has developed two types of basic form of study: public and private Children Musical Schools (CMS). Leading public CMS of China are: the Primary School under the Central Conservatory and the Primary School under the Shanghai Conservatory. They accept children aged from 9-10 to 12 years who have passed the entrance examinations; but, however, preference is given to those who demonstrate the inborn talent for music. Studying is carried out on a three-year education program. It includes not only the basic technical exercises (gammas, chords, arpeggios, gammas by double notes - in thirds, sixths, octaves), and etudes (Czerny, Cramer and others), polyphony (J. S. Bach, G. F. Handel and others). In addition, in the education program piano pieces by the Chinese composers are widely used. These schools select talented children and recommend them to enter the Conservatory for the further special education. Working on professional education, the schools also attach great importance to the general growth of students. In the curriculum, in addition to music, there are general educational subjects, including Philology, Mathematics, Foreign Languages, Computer, etc.

Now the mass character of the musical education and the propagation of the overall music education in China became obvious. In recent decades, there were opened many private musical schools and courses that accepted everyone with no age restriction: for the preschool and preparatory education you should only submit an application for admission. In these schools the lessons are conducted by professors and teachers who work at the Conservatories and the Pedagogical Institutions, and graduates of musical schools as well. Classes take place at weekends or in the evenings. At pleasure, the children choose both the time of the classes, and the term of studying (without exams and tests). However, all students may participate in the state music certification and get the certificate of the achieved level.

Let's have a short look in the history.

After the formation of the Chinese People Republic (CPR) the period of 1949-1966 was the most significant stage of the development of the Chinese piano education. China made progress in many branches of human being, musical life being among them. Since 1953, two leading conservatoires - in Bejing and Shanghai - were taken under the rule of the Ministry of Culture, and the Piano Faculties became the basic centers of studying the piano art and its researching.

The Piano Faculty of the Shanghai State Conservatoire (SSC) integrated the Piano Department of the former Fuzhyan Musical College, the Piano Department of the Zinging Women' University, the musical faculty of the Eastern China Pedagogical Institute. The famous musician Khe Lutin was the first vice-rector of the SSC, professor Lee Zuzhen was the Dean, Fan Zsishen-a Vice-Dean.

Firstly, the Central State Conservatoire (CSC) was situated in Tyansin, then it moved to Bejing. CSC was organized on the basis of integration of the Nankin State Conservatoire, the Musical faculty of the Bejing State Art Institute, the musical faculty of the Yanking University, the musical faculty of the Culture and Art Institute named after Lu Sing, the musical faculty of the Northern-Chinese University, the Conservatoire in Syangan. The Dean of the Piano Faculty was I Kajzsi, a Vice-Dean-Ju Gun-i. 
An effective subsequent system of teaching based on the Soviet experience was created in SSC and CSC. It included studies in the primary school (4 years), musical college under the conservartoire (6 years). Some of the graduates of the conservatoire entered the postgraduate course - aspirantura (2 years). 16-year period of the overall education ensured the high level of the graduated professional pianists.

The conservatoires focused their special attention on the improvement of the teachers' professional level. High standards were produced concerning in the use of the miscellaneous piano literature. Piano classes selected the best pupils that became later young teachers, experienced specialists helped them to master secrets of teaching piano playing. A list of the best topics of the scientific investigations was composed in the CSC every year, the teachers had to choose a question, work on a problem and compose an article, report or a program of a recital in order to contribute to the improvement of the teaching and learning process.

There was in SSC and CSC a so called Executive Committee which composed a plan of annual concerts and adopted their programs. For example, there were organized concerts dedicated to the national holidays, jubilees of higher schools and their leading specialists. Besides this, the departments arranged summary concerts on week-daysonce in 2 weeks, in order that a pupil could play not less than 2 times in a semester, if he did not do it, he was not allowed to pass the State exams.

In each administrative center and in some of the big cities in China there were held musical institutions. In 1952-1953 the special Musical Studio of the Northern-East China (Shenyan), the Musical Studio of the Southern-West China (Chendu) and the Musical Studio of the Middle-South China (Ukhan) were opened. Sian Musical Studio appeared in 1956, Guanzhou Musical Studio-in 1958. These studios became conservatoires later: Shenyan, Sychuan, Ukhan, Sian, Sinkhai. Tanzsin conservatoire was opened in 1959. In each conservatoire there were piano classes. Musical faculties of some pedagogical institutions had piano classes and departments as well. Particularly, the faculties appeared in the pedagogical institutes of provinces Khunan, Ankhu, Fuzsyan, etc. Many of the conservatoire graduates associated their process of professional development with the humanitarian local practice and worked on the popularization of the piano art.

Education institutions were required to teach music both-for young musically educated public and for those who wanted to become professional musicians. These schools educated musical aesthetic capabilities and creative thinking of students, helped children to realize the importance of cooperation and humanitarian training to promote comprehensive development of personality. We mention the most famous of them: 'Mass piano school named after Nieer' in Shanghai, 'Mass piano school', 'Piano school named after Iyuya', 'Piano school for children named after Qinghai' in Beijing, 'Piano center' in the cities Guangzhou and Taiyuan.
The famous pianist Zhou Guayazhen was the Head of the 'Piano school for children named after Qinghai' in Beijing for 6 years (1983-1990). The school had at that time 300 graduates, 91 among them getting a diploma for the initial course, 29-awards of different city competitions. 10 pupils of the School were accepted later for studying at the professional institutions-specialized musical schools, colleges by conservatoires. Now, professor Zhou Guayazhen (she was one of the first Chinese executors in the 50s of the $20^{\text {th }}$ century who had won prestigious awards at international competitions) devotes herself to public awareness activities, she works on the popularization of piano teaching in wide layers of population in China. She visits local organizations in different cities and towns of China regularly, consulting teachers of piano, gives lectures on the Central TV, their topics dealing with the primary stage of studying piano playing. The public awareness activities of the pianist are compared in Chinese musical circles with the activities of the Gnessins, famous Russian musicians: the same type of a musician-enlightener. Zhou Guayazhen continues to play recitals and regularly takes part as a juror in Chinese and international competitions.

Two Central State Schools have brought up many outstanding talented pianists who got their first prizes at the international piano competitions, and have increased the influence of Chinese piano art on world culture. At the same time, they laid strong foundations for the development of Chinese piano art of our days and continue to play an important role in the Chinese piano education.

Many talented young pianists appeared thanks to the Musical School of the Central Conservatoire. Lang Lang, the most miraculous in the history of the Chinese piano playing and, in whole, in the history of artistic careers of pianists of the $20^{\text {th }}$ century - is among them. He began his studies at three and entered the Musical School under the Central Conservatoire when he was five years old. Lang Lang got first Prizes at the competitions in Shenyang and Beijing, in 1994 he showed himself brilliantly at the Fourth International Competition of young pianists in Germany, in 1995-became the winner of the First International Junior Competition named after Tchaikovsky in Japan. The triumph of the 17-year old pianist began after the performance in 1999 with the Chicago Symphonic Orchestra under the conduction of Daniel Barenboim. After graduating the Central Conservatoire Lang Lang leaved for the USA to continue his studies at the Curtis Institute in Philadelphia (class of the professor Harry Graffman). At the Festival in Ravinia in the 'Concert of the centenary' he replaced A. Watts who suddenly had fallen ill. In a year Lang Lang brilliantly made his debut in the New York Carnegie-Hall with Yury Temirkanov, and then-at London Festival $B B C$ Proms. After these performances 'The New York Times' named him 'the most bright executor of the classic music'. His unprecedented popularity may be compared with the popularity of a pop-star. 


\section{PRINCIPLES OF FORMATION THE NATIONAL WAYS OF TEACHING IN THE ChINESE PIANO METHOdicS}

Although the piano came to China only about 100 years ago and the Chinese piano music doesn't have centuries-old history, the piano art almost immediately became the object of special attention of Chinese educators and composers. By the reason of the fact that cultures of China and Europe are different, the traditional European piano method cannot fully meet the characteristics of Chinese education. Therefore, the formation of national methodology is a priority in piano pedagogy.

For the formation of a performing school it is important not only the mass of education, number of educational institutions, the success of individual musicians in the international arena. It must be described by actual methodical principles in technology of education and interpretation of the classics, its own national repertoire, original, related with national tradition, performing concepts, as well as the sequential succession among the generations of musicians. In a long process of checking by practice Chinese teachers continuously improve their professional level and create their own principles of forming the piano methodology and methodic.

\section{A. Interactions Between Technical Training and Chinese Art Aesthetics}

As for methodic ideas, Chinese piano education aims a strong focus on purposeful formation of the technical apparatus from an early age, this attitude has a priority. For students the main task is to train their fingers and hands; for these purposes, the European didactic literature, mainly instructive, is widely used [3, p. 3].

A widespread practice in traditional musical pedagogy of China is a long keeping of children (for several years) on the same exercises, in particular, of the well-known in Russia Sh. L. Ganon. His exercises are designed to develop fluency and strength of fingers, their even development. Collections of etudes by Czerny-Germer and Czerny's Etudes op. 299 are frequently used. This 'drill', of course, is not liked by most of children; with greater pleasure they play the etudes that look like a beautiful piece-with a pleasant melody and built harmony. As the repertoire at the initial stage of studying etudes of a French composer and pedagogue, a German by birth, Friedrich Burgmueller (1804-1874)--25 Easy Etudes op. 100 and Etudes op. 105-for more advanced students - can be called popular.

Exercises and etudes accompany the whole period of studying, although after mastering these collections most of the teachers also use 'Children's album' by P. I. Tchaikovsky, and pieces by J. S. Bach from 'The Musical notebook for Anna Magdalena Bach'. The principle of studying of these collections is to play everything, without learning by heart and careful finishing. The studying process is more focused on posing hands, rather than deep familiarity with the content of the music, with difference in musical styles. However, the bright, memorable pieces of Burgmuller, Bach, and Tchaikovsky still delight children against never-ending exercises, gammas and etudes.
The result of such teaching methods is quite strong and really massive technical equipment of children studying piano. Focus on the development of your finger dexterity and freedom of movement of hands should be considered the main feature of Chinese piano pedagogy. However, such techniques do not contribute to the actualization of creative potential of a child and formation of his personal position in the process of communication with music.

At the same time, many Chinese pianists and teachers use some principles of Chinese artistic aesthetics in their performance practice and pedagogy differently. Renowned pianist and teacher Zhu Gong believed that it is necessary "... to teach, relying on the natural abilities of students ... a good teacher does not force students his own taste but contributes to the formation of their own" [5, p. 32]. To teach a pianist's thinking and imagine in his classes Zhu Gong played a little, but often talked about the composers, the content and the sense of work and style. Considering that the types and techniques of different students have individual colors, Zhu Gong helped to acquire technology basing on natural instincts. He was against giving students' practice technique much time. He was very concerned about the sound, and spent the analogy with paints and palette of an artist.

Chinese pianists borrow the principles of correlation between feelings and their expression through the physical action from folk theatre, art, ancient philosophy. The Chinese national theater acting in very restrained manner, even if the characters are in anger or rage, their poses are never harsh and provocative. Untrained viewers sometimes get the impression that the form and expression means of Chinese art are far from reality. But everything that Europeans often perceived as a convention is clear and close to the Chinese people and consecrated by millennial traditions. Rituality characterizes the Chinese in their regular affairs and in the tragic situations.

The Chinese philosophy is characterized by a high degree of concentration in view of the world, translated from the Chinese it means - 'the feeling and the conditions'. If the 'feeling' and the 'conditions' are in balance (the Golden mean), than the execution reaches 'a high degree of thought concentration'. "The principle of the golden mean, which was recognized and justified even by Confucius, to some extent, can be an obstacle in the expression of human individuality, life characters and prototypes, individual qualities of the artist - all that has found the implementation in rich experience of European art" [2, p. 103]. On the basis of these provisions it becomes clear why the critical attitude to the bold, open external expressions is widespread in the Chinese piano pedagogy.

Critics noted a distinctive feature of the Chinese pianists on the stage that seems at first glance, even contradictory. On the one hand, there are the simplicity and clarity of style; on the other hand, there is modesty in emotional expression. However, this contradiction is imaginary and related to the specificity of Chinese art in general, with the predominance of two styles. The first style is 'Wen'- 'rest', as it is characterized in the pedagogical literature. This is a high degree of thought concentration, awareness of the feelings 
and conditions. If you reach the 'golden mean', you're your performing style is perfect. Such a way of performing is the most productive in the interpretation of lyrical works, or transmitting the deep and soft mood in music, or the embodiment of the subtlest gradations of sound.

At the other end of the piano performing arts of China is the style of ' $W u$ '-'warlike'. There are too many feelings and emotions that, according to many Chinese teacherspianists, can destroy the principle of 'golden mean', so important for Chinese culture. This is the reason for the fact that Chinese pianists prefer works in 'Wen' style. However, in the first decade of the $21^{\text {st }}$ century the style ' $W u$ ' was widespread (for example, a well-known Chinese pianist Lang Lang plays in this executive manner), and in practical pedagogy two styles balanced each other.

\section{B. Chinese Recreational System Qigong in the Method of the Initial Piano Education}

The doctrine of special performance style, as well as the use of the Chinese recreational system «Qigong», in the methods of piano playing has purely national features. As we know, Qigong - is the art of physical and mental health promotion, practiced in China. Qigong allows increasing the possibilities of human mind, control the body, strengthening the functions of the human body, strengthening and developing its hidden features.

In 1991, at a meeting on piano technique two famous professors-Zhao Xiaoshen (Shanghai) and Fan Yuanqi (Shenyang)_-gave presentations on the topic 'How the ancient doctrine Qigong can help the piano performers'. They explained in their reports that physical self-control involves the ability to be 'centered', put the body in balance and, most importantly, to relax for $Q i$ circulating.

During the performance, it is necessary to regulate the movement of internal energy $Q i$. This movement occurs simultaneously with the extraction of the instrument sound, and manifests itself through sound. Coordination of $Q i$ requires proper breathing, in particular, it is necessary to breathe with the syllable ' $Q i$ ' at the beginning of a musical phrase, and breathe out during the end of a phrase or sentence. The fact is that you first need to understand the melody by your heart, then ' $q i$ ' should penetrate into the fingers. Before the execution you should seat straight, the body should be free, and in addition, you need to focus. During the performance, the hands should move in accordance with the movement of Qi. All that is in accordance with this movement looks naturally and freely.

Thus, the principles of Qigong are introduced in China piano performance to form the unity of the inner spirit and external manifestations of pianist's actions, which contribute to solve many of the problems associated with playing the piano. For example, practicing hands relaxation, body coordination and the elimination of tension, etc. Such techniques help an artist to understand the nature of a problem and to solve it quickly.

\section{Use of the Creativity of Chinese Composers in Piano Repertoire}

Chinese cultural tradition has influenced piano art in our days and before, this is due to the feature of Chinese thinking, thanks to the peculiar system of Chinese culture.

An important event of Chinese history was the first competition named 'Chinese piano works', organized by the famous Russian composer Alexander Cherepnin. This event had a profound influence on the development of Chinese piano. At the competition six works were awarded prizes, they expressed the traits and characteristics, which have become largely typical for the Chinese piano works: attraction to clear melodic style, the sound transparency, compact texture, not overloaded with ponderous chord succession.

The works by Chinese composers influenced the formation of Chinese professional composers' school and the development of children's piano training. Among these pieces are: He Lvding 'Small cowboy's flute', Lao Zhicheng 'Song of the shepherdess', Jiang Dingxiang 'Lullaby', etc. On the new stage the Chinese composers possessing specifics of piano and modern equipment, using different genres of folk music-making, arrange songs and tunes of the Chinese folk music and compose original works for children. These miniature opuses should be concise, usually no longer than 5 minutes, so that children from an early age could be acquainted to a variety of folk music culture. The use of these works in the educative process will not only contribute to the musical development of young pianists, but enrich them in general, as well.

Chinese piano music is the direction of the composers' work, largely based on the traditional musical culture. Virtually all modern music for children has grown on the basis of national traditions. Chinese composers are trying to find new, improved methods for expressing national musical sensations, close to the emotional world of a child.

\section{METHOdOlOGY OF THE PRIMARY PiANO EDUCATION IN CHINA: AS A SYSTEM}

In the early years of founding the People Republic of China (PRC), methods of teaching piano only repeated the conquest of European schools. In the both basic conservatoires there were many specialists who had studied abroad previously: Li Cuizhong - in England, Li Jialu and Xia Guojun - in the USA, Wu Leyi-in France. They implemented in the educational process a comprehensive pedagogical material taken from piano practice of European and American conservatories, which expanded the students' horizons and promoted the comprehensive development of various styles. At the same time, famous foreign teachers worked in China to improve the professional level of studying piano. Having rich experience and using advanced techniques, they organized workshops in different parts of the country and contributed to the development of the Chinese piano technique.

Up to the 60s theoretical researches in the field of piano pedagogy and technique were performed very poorly. In 
China, many responsible teachers, learning the Soviet or Eastern European piano technique used their principles and methods in the practice of training and performance, however, with the exception of some individuals, no one was aware of the need for a generalization of provisions needed to create a unified theory. In 1959, the Chinese Musical Union issued a three-volume collection of 'Musical art', which included 134 papers, written in the first decade after the formation of the PRC. But none of the volumes had information about the problems concerning the method of learning to play the piano. Although, since 1950 China had published several magazines about professional music studies, they placed only five articles on the problem: Hong Shikui 'Issues of self-directed learning to play the piano' (magazine 'Folk music', number 8, September 1956 ), I Kaiji 'My view on the development of piano playing' ('Folk music', number 4, 1962), 'Some considerations about the basics of piano technique' (composed by the piano faculty of the Shanghai Conservatory; 'Folk music', number 10, 1962 ), 'Pedagogical ideas about teaching adult the piano' (published by the Central Conservatory of China in 1959), 'About the most efficient and effective ways of learning the piano' (magazine 'Music education', 1958). Due to the fact that at that time in China had not yet been formed the sphere of theoretical researches of Chinese piano, there were obstacles to the development of piano activity.

Work in the field of methodological and theoretical studies was revived in 1979. In China between 1979 and 1990 there were published more than 110 scientific articles on the piano technique. Their content was largely reduced in several trends to: teaching the piano, teaching a general course of piano, acquaintance with the experience of some famous teachers, how to teach the piano adults and children. Currently pianists build their teaching activities through the use of advanced performing experience, relying on the world's best traditions and achievements in the field of piano pedagogy. Among the works on pedagogy and performance are highlighted the books: Ying Shizhen 'Piano Pedagogy' (1990), Ge Deyue 'Piano Pedagogy Zhu Gong' (1989), Zhao Xiaoshen 'The way to the piano playing' (1991).

In 1990, the book by Ying Shizhen 'Piano Pedagogy' [6] was published in Beijing. It was the first, written by a Chinese woman work on methods of teaching to play the piano, which allowed to judge about some of the important principles of piano pedagogy in China. Among the main issues, presented in this book, were the character and the role of a teacher, the content of initial training, polyphonic performance training, the use of the pedal, the psychological preparation of an artist and executor. The final part of the book deals with the conditions and principles of a successful teaching process.

Ying Shizhen pays particular attention to the initial stage of learning the piano playing, believing that in the early years lay the basic, fundamental tools that are required for the formation of a really professional artist. She claims that at the initial stage of learning, teacher must be aware of the specifics of his work: a successful professional pianist development cannot be without establishment of the optimal methods and teaching techniques, the correct definition of the object of study, the sequences in mastering an arsenal of expressive means, the rational organization of the learning process.

The author pays special attention to the development of technical and psycho-physical skills, auditory control and operation of consciousness, the unity of rhythm and uniform of the even speed in the performance of music - all this determines the methodology. The author also attaches great importance to installing in pupils a proper understanding of polyphonic piano music. She accustomed students to listen to two-handed performance, its extent, development, distinguish timbre in different voices, comparing choir (vocal) and piano (instrumental) polyphony.

Ying Shizhen has acquired great practice, working at the Beijing Conservatory, and could generalize the achievements, correlate them with the experience of other Chinese pedagogues, and then set out in writing. Her research was very important for elementary Chinese piano pedagogy; it has contributed to increasing popularity of piano in contemporary China.

In October 1991, the PRC Ministry of Culture held a meeting on issues of piano technique. It was attended by more than 300 professionals, most of whom were teachers of conservatories, universities, art institutes and secondary educational institutions. The meeting lasted for 6 days, more than 40 teachers made their reports concerning issues of pedagogical practices and teaching methodologies. Here are some of the topics: 'The basis of training, skills and knowledge of the final result' (Zhou Guangren), 'Natural qualities of pianists' (Yang Jun), 'Positive experience and failures of piano pedagogy at the school' (Li Xiaoling), 'Some considerations on the development of skills of independent work of students' (Liu Chanpiao), and so on [5, p. 116].

At the end of the meeting all the participants pointed out the common problems of Chinese piano education in the final document: the lack of the professional piano teachers, the necessity to improve the professional level of young teachers and improve the testing of knowledge level, and in particular - the need to care about the fate of young talents, solvation the problems of their further education and employment.

\section{COMPARATIVE ANALYSIS OF THE FIRST MEETING WITH MUSIC By ANNA ARTOBOLEVSKAYA AND PIANO PEDAGOGY BY YING SHIZHEN}

It is very interesting to make a look at the training appliances for the primary stage of teaching the piano playing. In Russia the most popular is The first meeting with music by Anna Artobolevskaya [1], in China no less popular is Piano Pedagogy by Ying Shizhen [6]. The both authors are sure that the primary stage of studying is the basic for the further way of bringing up a musician, it is valuable in the teaching and learning process.

Ying Shizhen considers that the majority of pupils start with piano studies early when the teacher is playing a big, almost, the main role in their musical upbringing. Anna 
Artobolevskaya is sure that in the beginning the home environment is not less important than the teacher's activities.

During the first meeting Ying Shizhen and Anna Artobolevskaya test musical abilities of a pupil differently. Ying Shizhen includes singing of a song with the words, Anna Artobolevskaya checks the child's intonation using a convenient vowel.

Questions of setting by the instrument are stated in both appliances. The authors agree that you have to sit on the half of a chair, the upper part of the body demands a straight position, with a light forward pitch, position of waist must not be disturbed, support position is made from above and forward to the fingers. Artobolevskaya points out that a child should have a stand to learn how to lean on it with his heels.

The both authors consider that a teacher has to make staging the hands imperceptibly, gently, with the help of his own hands. Artobolevskaya proposes some exercises of a special gymnastics to free the pupil's body.

The main difference in the method lies in the approach to the process: Artobolevskaya is building the learning process like a game, that is psychologically very true concerning the age of pupils, Ying Shizhen, whose system became basic in China, treats the primary stage only from the professional and theoretical positions. There is one more difference: Artobolevskaya adds a pre-note period, but Ying Shizhen starts studying note grammar from the very beginning.

The comparative analysis shows that there are similarities and some differences in the methods written in the most widespread in Russia and China training appliances dedicated for the primary leaning process in studying the piano playing with children.

\section{SUMMARY}

Looking through our investigations it must be stated that the methodology and methodic of the primary teaching the piano in China is on the stage of formation, especially concerning the forms of national methods. It is a product of the Chinese musical education absorbing national traditions. Though the piano art does not have in China a long history as in Europe, it is connected with social-historical conditions and is subjected to their influence as everywhere. Accompanying strategic policy of 'reforms and interconnections', the primary musical education in the new period and in the new environment gained a new significance, its social and artistic status must not be ignored, because it has become one of the basic supports of All-China national education.

There are two main forms of teaching playing the piano in China: state and private Children Musical Schools. They laid down the foundation for the development of the Chinese piano art. At the same time, the Chinese teachers improve their professional level constantly and are working on forming a national piano methodic system.

The peculiarities of existing Chinese national methods of teaching piano playing on the primary stage include:
- presence of two forms of education-public and private music schools;

- priority of technical training;

- development of two performing styles- 'Wen' and ' $W u$ ';

- involvement of the Chinese Qigong system;

- development of the creativity of the Chinese composers for children.

Different technologies have already been formed, and they require further observations of their development, issuing textbooks and other types of publications, as well as a want for a new research, including experimental activities.

Our recommendations are:

- to conduct pedagogical experiments on the base of the Chinese musical schools;

- the aim of the investigations must be solving the basic questions of the methodic of primary teaching in China the piano playing.

\section{REFERENCES}

[1] Anna Artobolevskaya. The first meeting with music: training appliance. Saint-Petersburg: Composer*Saint-Petersburg, 2009. 101 p. [Artobolevskaia A. Pervaya vstrecha s musykoi: uchebnoye posobiye. Sankt-Peterburg: Kompozitor*Sankt-Peterburg, 2009. 101 s.]

[2] Bian Meng. Essays on the formation and development of Chinese piano culture: Diss.... cand. Arts. St. Petersburg, 1994. 142 p.

[3] Hou Yue. Children piano education in China and problems of its development: Diss.... cand. Arts. St. Petersburg, 2009. 183 p.

[4] Ge Deyue. About piano pedagogy of Zhu Gong. Beijing: Folkmusic, 2009. 222 p.

[5] Joan Dean. Piano education. Beijing: Publishing office of Association of Literature and Art of China, 2003. 231 p.

[6] Ying Shizhen. Piano pedagogy. Beijing: Folk music, 2007. 194 p. 